\title{
Nonpathogenic Binucleate Rhizoctonia spp. and Benzothiadiazole Protect Cotton Seedlings Against Rhizoctonia Damping-Off and Alternaria Leaf Spot in Cotton
}

\author{
Suha Jabaji-Hare and Stephen M. Neate
}

First author: Plant Science Department, Macdonald Campus of McGill University, 21,111 Lakeshore Rd., Sainte-Anne-de-Bellevue, Quebec, H9X 3V9 Canada; and second author: Department of Plant Pathology, North Dakota State University, P.O. Box 5012, Fargo 58105. Accepted for publication 18 April 2005.

\begin{abstract}
Jabaji-Hare, S., and Neate, S. M. 2005. Nonpathogenic binucleate Rhizoctonia spp. and benzothiadiazole protect cotton seedlings against Rhizoctonia damping-off and Alternaria leaf spot in cotton. Phytopathology 95:1030-1036.

Recent reports have shown induction of resistance to Rhizoctonia root rot using nonpathogenic strains of binucleate Rhizoctonia spp. (np-BNR). This study evaluates the biocontrol ability of several np-BNR isolates against root and foliar diseases of cotton in greenhouse trials, provides evidence for induced systemic resistance (ISR) as a mechanism in this biocontrol, and compares the disease control provided by np-BNR with that provided by the chemical inducer benzothiadiazole (BTH). Pretreatment of cotton seedlings with np-BNR isolates provided good protection

against pre- and post-emergence damping-off caused by a virulent strain of Rhizoctonia solani (AG-4). Seedling stand of protected cotton was significantly higher $(P<0.05)$ than that of nonprotected seedlings. Several $n p-B N R$ isolates significantly reduced disease severity. The combination of BTH and np-BNR provided significant protection against seedling rot and leaf spot in cotton; however, the degree of disease reduction was comparable to that obtained with np-BNR treatment alone. Significant reduction in leaf spot symptoms caused by Alternaria macrospora occurred on cotyledons pretreated with np-BNR or sprayed with BTH, and the npBNR-treated seedlings had significantly less leaf spot than BTH-treated seedlings. The results demonstrate that np-BNR isolates can protect cotton from infections caused by both root and leaf pathogens and that disease control was superior to that observed with a chemical inducer.
\end{abstract}

Protection against damping-off and crown and root rot diseases caused by Pythium Pringsh. spp. and Rhizoctonia solani Kühn has been reported in greenhouse or field trials of young seedlings of many crops treated with nonpathogenic binucleate Rhizoctonia spp. (np-BNR) $(9,23,25,31,44,53,56)$. The np-BNR protectors in these studies belonged to the anastomosis groups (AGs) AG-A, AG-B(a), AG-B(o), AG-G, AG-I, AG-K, and AG-P (52). With poinsettia cuttings (31), corn (44), soybean (45), and bean (34), np-BNR isolates have been shown to act as inducing agents, leading to systemic resistance against $R$. solani. In the Rhizoctonia stem rot and Colletotrichum anthracnose pathosystems on bean, the np-BNR strain 232-CG was shown to elicit induced systemic resistance (ISR) in the stems and the cotyledons to later challenges with the root rot pathogen $R$. solani (AG-4) or the foliar pathogen Colletotrichum lindemuthianum (Sacc. \& Magnus) Lams.-Scrib. (59). In addition, the np-BNR isolate elicited a significant and systemic increase in total peroxidases, $1,3-\beta$ glucanases, and chitinases compared with the diseased and control plants, and this increase was negatively correlated with disease incidence (59).

Cotton (Gossypium hirsutum L.) is the most important fiber crop grown worldwide in over 90 countries, and Australia is the third largest exporter in the world cotton marketplace, after the United States and Uzbekistan. Cotton seedlings are vulnerable to attack by a number of soil- and seedborne pathogens, including $R$. solani (57), the causal agent of pre- and post-emergence damping-off, and Alternaria macrospora A. Zimmerm. (57), a causal agent of cotton leaf spot. Severe infection by A. macrospora can

Corresponding author: S. Jabaji-Hare; E-mail address: suha.jabaji-hare@mcgill.ca

DOI: 10.1094/PHYTO-95-1030

(C) 2005 The American Phytopathological Society lead to premature defoliation of susceptible plants (27). Both fungi occur in most of the cotton-growing areas in the world, and the diseases that they cause often result in substantial stand loss, especially in young cotton seedlings (47). Despite the effectiveness of fungicides, their widespread use has not eliminated cotton seedling damping-off or Alternaria leaf spot (3). Moreover, the widespread use of fungicides is heavily scrutinized by the public, mainly due to their potential harmful effect on nontarget organisms and the environment. Thus, there is a need to examine alternative approaches to cotton disease management, such as biological control and the nontoxic chemical inducers or activators of resistance.

Protection against cotton seedling damping-off in greenhouse and field trials has been achieved using various biological control agents such as Trichoderma spp. and Gliocladium virens $(19,28$, 29,39), plant-growth-promoting rhizobacteria (PGPR) (19), Bacillus subtilis (2), and Pseudomonas cepacia (60). Suppression of Alternaria leaf spot in cotton has been successfully achieved following application of 2,6-dichloroisonicotinic acid (INA) and benzothiadiazole (BTH), two thoroughly investigated chemical inducers of resistance $(7,10,11)$. These nontoxic, synthetic chemicals act as strong elicitors of plant defense reactions and are known to mimic the role of salicylic acid (SA) in signal transduction, leading to induced resistance and enhanced broad-spectrum protection against pathogens $(41,46)$. Current models of ISR assume acropetal translocation of soluble molecules with potentiation of resistance in aerial tissues $(20,37)$. Hence, most available data concern effects on foliar pathogens, such as leaf blights, powdery mildew, and downy mildews. Much less research had been conducted on the effect of these chemicals on pathogens infecting basal stem tissues and roots $(4,5,8,35)$, and there is no available data on the effect of either chemical inducer on dampingoff diseases in cotton. 
The objectives of this study were to (i) evaluate, under greenhouse conditions, the protective ability of several Australian npBNR isolates against post-emergence damping-off of cotton and investigate their ability to induce resistance; (ii) test whether the resistance response is systemic and nonspecific, by using A. macrospora as a challenge inoculum on cotton cotyledons after their roots had received an induction treatment; and (iii) compare np-BNR with BTH foliar treatments for their efficiency in enhancing resistance against both pathogens.

\section{MATERIALS AND METHODS}

Biological material. Cotton seed of cv. Siokra V15 were surface sterilized in $1 \%(\mathrm{vol} / \mathrm{vol})$ sodium hypochlorite solution for $10 \mathrm{~min}$, then rinsed with sterile deionized water. Depending on the experiment, the seed were either (i) germinated in trays of water-soaked and drained vermiculite and grown at $25^{\circ} \mathrm{C}$ in the dark for 7 days or (ii) sown $2 \mathrm{~cm}$ deep in pots containing field soil.

Details of the np-BNR and the pathogens $R$. solani AG-4 and A. macrospora are provided in Table 1 . Inocula of np-BNR and $R$. solani consisted of mycelium growing on agar strips from the periphery of 1-week-old potato dextrose agar (PDA) cultures or colonized wheat kernels which had been sterilized, inoculated, and grown for 2 weeks before air drying prior to use (59). Conidia of $A$. macrospora were produced by inoculating a 1-week-old PDA plug onto the surface of V8 agar and incubating for 12 to 14 days at $22^{\circ} \mathrm{C}$ under a 12 -h photoperiod illuminated by black light and cool white fluorescent tubes (7). A conidial suspension was prepared by flooding the surface of the plates with sterile deionized water and scraping the surface gently with a sterile glass rod to suspend the conidia. Inoculum consisted of conidial suspensions of $1.5 \times 10^{5} \mathrm{conidia} / \mathrm{ml}$. All np-BNR isolates were maintained on PDA slants under oil, $R$. solani was maintained on sterile millet seed (24), and A. macrospora on V8 agar slants. Unless otherwise stated, the pathogens hereafter are referred to as the challengers and the binucleate nonpathogenic isolates are referred to as protectors.

Chemical inducer. The BTH compound used, benzo(1,2,3)thiadiazole-7-carbothioic acid S-methyl ester, was the commercial product Bion, which is in granular form and contains $50 \%$ active ingredient (a.i.) (Ciba-Giegy, Basel, Switzerland). Solutions of 20 and $50 \mathrm{ppm}(\mu \mathrm{g} / \mathrm{a} . \mathrm{i} . / \mathrm{ml})$ in deionized water containing $0.02 \%$ Tween 20 ( vol/vol) were prepared on the day of application. BTH was sprayed to run-off on fully expanded cotyledons of 1-weekold cotton seedlings using a model V Paasche artist's airbrush (Paasche Airbrush Co., Harwood Heights, IL).

Experimental series. Experiment I: in vitro screening of $n p$ $B N R$ for pathogenicity on cotton. Fifteen isolates were assayed for pathogenicity on cotton using etiolated cotton seedlings germinated in vermiculite in the dark for 1 week at $24^{\circ} \mathrm{C}$. Seedlings were carefully removed from the vermiculite, washed with sterilized deionized water, blotted dry, and transferred to sterile aluminum trays ( $38 \mathrm{~cm}$ long by $27 \mathrm{~cm}$ wide by $6 \mathrm{~cm}$ high) lined with wet sterile paper towels. Seedlings then were subjected to one of the following treatments: (i) inoculated with 1-by-5-cm agar culture strips from 1-week-old np-BNR cultures on PDA, (ii) inoculated with 1-by-5-cm agar culture strips from 1-week-old $R$. solani culture on PDA, and (iii) inoculated with sterile 1-by5-cm PDA strips. Inoculation of all seedlings with either np-BNR or $R$. solani were across the hypocotyls, the bottom edge of the strip $3 \mathrm{~cm}$ from the roots. A replicate of each treatment was a group of four etiolated cotton seedlings that were placed on moistened, sterile, 9-cm-diameter Whatman No. 42 filter paper and placed over the paper towels in the trays. Each treatment had two replicates. Roots of all seedlings were covered with moist, sterile, absorbent cotton wool. The aluminum trays were sealed with plastic film, returned to growth chambers, and incubated at $24^{\circ} \mathrm{C}$ for $48 \mathrm{~h}$ in the dark. All treatments were scored for disease severity using a disease index scale (DSI) from 0 to 5 according to the method of Cardoso and Echandi (9), where $0=$ no lesions on hypocotyls, $1=$ lesions $\leq 2.5 \mathrm{~mm}$ long, $2=$ lesions 2.5 to $5.0 \mathrm{~mm}$ long, $3=$ lesions $\geq 5.0 \mathrm{~mm}$ long, $4=$ lesions girdling the seedling, and $5=$ seedling is damped-off.

Experiment II: screening of $n p-B N R$ isolates for mycoparasitic activity. Hyphal interaction between R. solani AG-4 (1664) and the 15 isolates of $\mathrm{np}-\mathrm{BNR}$ were studied in $3.5-\mathrm{cm}$ petri plates on sterilized cellophane membrane overlying water agar (50). Mycelial plugs ( $5 \mathrm{~mm}$ in diameter) from $R$. solani and from each of the $\mathrm{np}-\mathrm{BNR}$ isolates were cut from the margin of actively growing colonies and placed on the surface of the cellophane membrane separated by a distance of $2 \mathrm{~cm}$. Control plates were inoculated with both plugs of the same np-BNR isolate or two plugs of the $R$. solani isolate. Dual cultures and controls were incubated in the dark at $24^{\circ} \mathrm{C}$ for $24 \mathrm{~h}$. The interaction zone that consisted of intermingled hyphae of the two isolates was observed in situ under a light microscope to search for evidence of coiling, penetration pegs, and intracellular colonization of $R$. solani by the np-BNR isolates. There were three replicates for each combination.

Experiment III: suppression of $R$. solani with $n p-B N R$ isolates. To test the potential of np-BNR isolates to suppress hypocotyl rot caused by $R$. solani, etiolated cotton seedlings were subjected to the following treatments: (i) inoculation of hypocotyls with two PDA strips of np-BNR at $3 \mathrm{~cm}$ from the roots for $24 \mathrm{~h}$; (ii) inoculation of hypocotyls with strips containing the np-BNR isolates for $24 \mathrm{~h}$, after which the PDA strips were removed and hypocotyls were challenge inoculated at $4 \mathrm{~cm}$ above the np-BNR inoculation site with one PDA strip of $R$. solani for another $24 \mathrm{~h}$; (iii) inoculation of hypocotyls with one PDA strip containing $R$. solani; and (iv) mock inoculation of seedlings with clean agar strips (control treatment). Each treatment had four replicates and each replicate consisted of four cotton seedlings. Seedlings were incubated under conditions identical to those of experiment I, and the experiment was repeated. All treatments were harvested after the required period of incubation and scored for hypocotyl rot using the scale from 0 to 5 as in experiment I. Microscopic observations were used to verify that the np-BNR isolates only colo-

TABLE 1. Fungal isolates used in this study

\begin{tabular}{|c|c|c|c|c|}
\hline $\begin{array}{l}\text { Isolate } \\
\text { number }^{\mathrm{a}}\end{array}$ & $\begin{array}{c}\text { Original } \\
\text { designation }\end{array}$ & $\mathrm{AG}^{\mathrm{b}}$ & Host or source ${ }^{c}$ & Ref. $^{\text {d }}$ \\
\hline \multicolumn{5}{|l|}{ BNR } \\
\hline 1707 & $\mathrm{C} 1 \mathrm{~B} 2$ & AG-F & Baited wheat & 1 \\
\hline 1709 & C1B4 & AG-F & Baited lupin & 1 \\
\hline 1734 & CRE 5P1 & AG-F & Primula sp. & 1 \\
\hline 1743 & ENG 4B2 & AG-F & Baited wheat & 1 \\
\hline 1745 & ENG 4B4 & AG-F & Baited wheat & 1 \\
\hline 1751 & GR1 2P1 & AG-F & Cyclamen & 1 \\
\hline JF3N1-1 & $\ldots$ & AG-G & Fragaria $\times$ ananassa & 2 \\
\hline 1710 & BRE 1B1 & AG-I & Baited wheat & 1 \\
\hline 1711 & BRE 1B2 & AG-I & Baited lupin & 1 \\
\hline 1726 & O1S1 & AG-I & Soil & 1 \\
\hline 1754 & $\mathrm{~J} 1 \mathrm{~B} 2$ & AG-I & Baited wheat & 1 \\
\hline 1713 & BRE 1B4 & AG-I & Baited wheat & 1 \\
\hline 1739 & B1B3 & AG-K & Baited Brussels sprouts & 1 \\
\hline 1730 & CRE 5B1 & $\mathrm{AG}-\mathrm{R}^{\mathrm{e}}$ & Baited wheat & 1 \\
\hline 1731 & CRE 5B2 & $A G-R^{e}$ & Baited wheat & 1 \\
\hline \multicolumn{5}{|l|}{ Pathogens } \\
\hline 1664 & Ogle 4 & AG-4 & Cotton & 3 \\
\hline \multirow[t]{2}{*}{ DAR 62284} & $\cdots$ & Alternaria & & \\
\hline & & macrospora & Cotton & 4 \\
\hline
\end{tabular}

a $\mathrm{BNR}=$ binucleate Rhizoctonia $\mathrm{spp}$.

b Anastomosis group.

c Plants were grown in used plant nursery soil and Rhizoctonia spp. were isolated from those plants.

${ }^{\mathrm{d}}$ References: 1 = Mashuara et al. (40), 2 = Xue et al. (59), 3 = Ogle et al. (42), and $4=$ Brock et al. (7).

e Allocated to AG-R by pairing with tester CAG5 isolates. 
nized the designated inoculated sites and not the areas of the hypocotyls inoculated with $R$. solani.

Experiment IV: biocontrol potential of $n p-B N R$ against $R$. solani in natural soil. To evaluate the biocontrol potential of np-BNR in controlling Rhizoctonia damping-off and hypocotyl canker under natural conditions, $10 \mathrm{np}-\mathrm{BNR}$ isolates were tested for their ability to suppress Rhizoctonia damping-off and hypocotyl rot. Vertisol soil $(15,33)$ from Rhynie, South Australia was sieved to $3 \mathrm{~mm}$ and stored air dry at room temperature. Surface-disinfested cotton seed (three seed per pot) were sown at a depth of $2 \mathrm{~cm}$ in $300-\mathrm{ml}$ pots containing $360 \mathrm{~g}$ of soil maintained at field capacity (38.5\% water, wt/wt). At sowing, each cotton seed was planted with two wheat kernels colonized by an isolate of npBNR or, as a control, two sterilized wheat kernels that previously had been colonized. In pathogen-amended treatments, one wheat kernel colonized with $R$. solani was placed $2 \mathrm{~cm}$ deep in the center of the pot. The pots were arranged in a randomized complete block design in a controlled environment growth chamber with a photon flux density of $175 \mu \mathrm{mol} \mathrm{m} \mathrm{m}^{-2} \mathrm{~s}^{-1}$ and a day and night cycle of 14 and $10 \mathrm{~h}$, respectively, at $25^{\circ} \mathrm{C}$. Plants were watered to weight daily with deionized water to maintain the desired waterholding capacity. Four treatments were compared: (i) pots amended with np-BNR, (ii) pots amended with $\mathrm{np}-\mathrm{BNR}$ and with $R$. solani, (iii) pots amended with $R$. solani, and (iv) unamended pots. Each treatment had four replicates and the experiment was repeated. At 14 days, the number of seedlings emerged in each pot was recorded (pre-emergence and post-emergence damping-off) and plants were washed free of soil and assessed for hypocotyl rot using the method of Sweetingham and MacNish (54). Shoot dry weights were recorded.

Experiment $V$ : control of $R$. solani in cotton using mixtures of $n p-B N R$ and Bion, a resistance inducer. The objective of this experiment was to evaluate the potential of the chemical inducer $\mathrm{BTH}$ alone or in combination with selected np-BNR isolates in controlling $R$. solani. One-week-old cotton seedlings, grown under conditions identical to those in experiment IV, were sprayed with BTH to run-off at two different concentrations and then challenged inoculated with $R$. solani. The treatments were: (i) BTH at 20 or $50 \mathrm{ppm}$ applied to cotton seedlings that were not protected with np-BNR isolates, (ii) BTH at 20 or $50 \mathrm{ppm}$ applied to cotton seedlings that were protected with np-BNR isolates, (iii) cotton

TABLE 2. Pathogenicity of nonpathogenic binucleate Rhizoctonia spp. (np$\mathrm{BNR}$ ) isolates as determined by the development of disease symptoms (represented by a disease severity index [DSI]) on etiolated cotton seedlings inoculated with either the np-BNR isolates or Rhizoctonia solani ${ }^{\mathrm{a}}$

$\mathrm{DSI}^{\mathrm{b}}$

\begin{tabular}{lcc}
\cline { 2 - 3 } Isolate & np-BNR & R. solani \\
\hline 1707 & 0.50 & 4.63 \\
1709 & 0.62 & 4.13 \\
1710 & 3.38 & 4.88 \\
1711 & 3.13 & 4.75 \\
1713 & 0.86 & 4.50 \\
1726 & 2.75 & 3.50 \\
1730 & 0.81 & 5.00 \\
1731 & 1.50 & 4.75 \\
1734 & 0.50 & 5.00 \\
1739 & 0.50 & 4.00 \\
1743 & 0.63 & 5.00 \\
1745 & 0.63 & 4.13 \\
1751 & 2.88 & 5.00 \\
1754 & 0.63 & 4.00 \\
JF3N1-1 & 0.44 & 4.25 \\
\hline
\end{tabular}

a Disease $\times$ isolate, $P=0.002$; least significant difference $(\mathrm{LSD})_{0.05}=1.15$.

b DSI representing severity of developing lesions on a 0 -to-5 scale, where $0=$ no lesions on hypocotyls, $1=$ lesions $\leq 2.5 \mathrm{~mm}$ long, $2=$ lesions 2.5 to $5.0 \mathrm{~mm}$ long, 3 = lesions $\geq 5.0 \mathrm{~mm}$ long, $4=$ lesions girdling the seedling, and $5=$ seedling is damped-off. Numbers represent the means of two replicates within each treatment. Data represent the results of one experiment. seedlings protected with np-BNR isolates, and (iv) a control of nonprotected cotton seedlings sprayed with water containing $0.02 \%$ Tween. Three days after BTH treatment, plants were challenge inoculated with $R$. solani 1664 by placing one $R$. solanicolonized wheat kernel at a depth of $2 \mathrm{~cm}$ and in close proximity to the hypocotyl of each cotton seedling. Plants were returned to the controlled growth chambers for an additional 5 days. All plants were carefully removed from the potting soil by washing, and scored for root rot and shoot dry weight. Each treatment had four replicates and pots were arranged as a completely randomized design in controlled growth chambers. The experiment was repeated.

Experiment VI: protection of cotton seedlings from Alternaria leaf spot using $n p-B N R$ isolates. Protected and nonprotected cotton seedlings, grown under the same conditions as in experiment IV, were subjected to the following treatments: (i) np-BNR-protected seedlings challenge inoculated with A. macrospora, (ii) BTH-treated seedlings challenge inoculated with A. macrospora, (iii) untreated seedlings inoculated with A. macropsora, and (iv) the control untreated and nonchallenged seedlings. Fully expanded cotyledons of 10-day-old seedlings were sprayed to runoff with a $1.5 \times 10^{5}$ conidia/ml suspension of $A$. macrospora using a Paasche artist's airbrush. Controls were sprayed with Tween solution. BTH-treated seedlings were sprayed with BTH at $50 \mathrm{ppm} 3$ days prior to their challenge inoculation with A. macrospora. Pots were covered with clear polyethylene bags that were misted inside with sterile deionized water to increase humidity. Pots were incubated in the dark at $25^{\circ} \mathrm{C}$ for $48 \mathrm{~h}$ before removing the bags. After a further 4 to 6 days of incubation, lesion numbers were recorded. All treatments were replicated four times and the experiment was repeated.

Statistical design and analysis. Experiment III was a split-plot design and all other experiments were completely randomized block designs. Experiments I and III were analyzed using the statistical program Genstat (VSN International Ltd., Hertfordshire, UK) and all other experiments were analyzed using the statistical program Statistix (Analytical Software, MN). Data were tested for violation of assumptions of normality. When necessary, data were transformed by square root transformation before analysis of variance. Mean separation was accomplished using Fisher's protected least significant difference test at $P=$ 0.05. All experiments were repeated. In experiments I to III, data from one representative experiment is presented; in experiments IV, V, and VI, the data from the two experiments were pooled and analyzed together to increase the power of the statistical analysis.

\section{RESULTS}

Of the $15 \mathrm{BNR}$ isolates screened for pathogenicity on cotton, five AG-F isolates (1707, 1709, 1734, 1743, and 1745), one AG-K isolate (1739), one AG-G isolate (JF3N1-1), two AG-I isolates (1713 and 1754), and one AG-R isolate (1730) did not cause observable disease on cotton hypocotyls (rot score $<1$ ) when compared with seedlings that were infected with $R$. solani AG-4 $(P=$ 0.001 ) (Table 2). Some of the binucleate isolates caused a slight yellowish discoloration at the sites of inoculation, but these were different in color and shape from the necrotic, brown, sunken lesions caused by $R$. solani AG-4 (data not shown). These 10 isolates hereafter are referred to as nonpathogenic BNR (np-BNR). The other five isolates produced mild to moderate disease symptoms visually similar to those caused by AG-4 but with rot scores ranging from 1.5 to 3.5 . All seedlings inoculated with $R$. solani AG-4 showed severe rot symptoms, whereas those that were mock-treated were symptom free. Light microscopy observations of hyphal interactions between each of the $15 \mathrm{BNR}$ isolates and $R$. solani AG-4 provided no evidence of mycoparasitic activity such as coiling, penetration pegs, or intracellular colonization (data not shown). 
An in vitro experiment was conducted to test the ability of 8 of the selected $10 \mathrm{np}-\mathrm{BNR}$ isolates to suppress hypocotyl rot caused by $R$. solani AG-4 (Table 3). Isolate 1751 also was included because its pathogenicity was variable, with some replicates being nonpathogenic. The results show that, with all np-BNR isolates, there was a significant reduction in hypocotyl rot when seedlings were protected prior to challenge inoculation with $R$. solani compared with those that were challenge inoculated alone $(P<$ $0.001)$. However, not all of the nine isolates gave the same degree of protection. Highest protection was achieved with AG-F isolates 1751,1745 , and 1707 , which gave significantly more protection than 1754, JF3N1-1, and 1730.

TABLE 3. Reduction of root disease severity caused by Rhizoctonia solani by pre-inoculation with isolates of nonpathogenic binucleate Rhizoctonia spp. $(\mathrm{np}-\mathrm{BNR})^{\mathrm{a}}$

\begin{tabular}{lccc}
\hline & \multicolumn{2}{c}{ Disease severity index (DSI) } & \\
\cline { 2 - 3 } np-BNR & np-BNR + R. solani & $R$. solani alone & Reduction $(\%)$ \\
\hline 1707 & 1.04 & 3.30 & 68.4 \\
1709 & 1.35 & 3.79 & 64.4 \\
1730 & 1.88 & 3.92 & 52.0 \\
1734 & 1.21 & 3.67 & 67.0 \\
1739 & 1.33 & 3.58 & 62.8 \\
1745 & 1.00 & 3.30 & 68.7 \\
1751 & 0.88 & 3.17 & 72.2 \\
1754 & 1.67 & 4.04 & 58.7 \\
JF3N1-1 & 1.67 & 4.08 & 59.1 \\
\hline
\end{tabular}

a Data represent the results of one experiment. Disease, $P<0.001$, least significant difference $(\mathrm{LSD})_{0.05}=0.62$; LSD values for DSI are for comparison across a row. Isolate, $P<0.026, \mathrm{LSD}_{0.05}=0.60$; $\mathrm{LSD}$ values for DSI are for comparison within a column.

${ }^{\mathrm{b}}$ Numbers represent the average of four replicates.
In experiments conducted with field soils, all nine np-BNR isolates except for $\mathrm{np}-\mathrm{BNR}$ isolate 1709 provided significant protection against combined pre-emergence and post-emergence damping-off in protected cotton seedlings that were inoculated with $R$. solani (Table 4$)$. In these plants, the seedling stand was significantly $(P<0.0001)$ higher than that of diseased cotton seedlings that were not protected. The degree of protection against $R$. solani varied significantly between np-BNR isolates $(P<0.0001)$. In the absence of $R$. solani, there was no significant difference in percent seedling stand between protected cotton and the untreated control cotton seedlings. Protected seedlings challenged inoculated with $R$. solani gave significantly higher dry weights with eight of nine np-BNR isolates. When protected seedlings were examined for hypocotyl rot and necrotic lesions, only those that were inoculated with np-BNR isolates 1707, 1730, 1734, 1745, and 1751 had significantly lower rot scores compared with those that were inoculated only with the pathogen $(P=0.0002)$.

Foliar spray treatments of BTH without np-BNR isolates provided significant control of hypocotyl rot incidence for BTH at 20 and $50 \mathrm{ppm}(P=0.001)$ (Table 5). Treatment of cotton plants with any of the four np-BNR isolates provided highly significant and better protection against hypocotyl rot $(P=0.001)$. The combination of BTH and np-BNR did not enhance the control of the disease over the control obtained with np-BNR alone. Treatment of cotton seedlings with np-BNR isolates either alone or combined with BTH did not have an effect on total dry weight of the plants.

To demonstrate whether a resistance response of cotton as a result of np-BNR treatment was systemic and not specific to only soilborne pathogens, we tested the effect of np-BNR treatments on resistance of cotton cotyledons to infection by the foliar pathogen A. macrospora. The np-BNR treatments also were compared

TABLE 4. Survival, disease incidence, and dry weight of protected and challenge-inoculated cotton seedlings grown in natural soil ${ }^{\mathrm{a}}$

\begin{tabular}{|c|c|c|c|c|c|c|}
\hline \multirow[b]{2}{*}{ np-BNR isolate ${ }^{b}$} & \multicolumn{2}{|c|}{ Seedling stand $(\%)^{\mathrm{c}}$} & \multicolumn{2}{|c|}{ Hypocotyl rot score (0 to 5 ) } & \multicolumn{2}{|c|}{ Dry weight (g) } \\
\hline & + Rhizoctonia solani & $-R$. solani & + R. solani & $-R$ solani & $+R$. solani & - R. solani \\
\hline 1707 & $1.39(2.00)$ & $1.61(2.63)$ & 1.31 & 0.23 & 0.227 & 0.232 \\
\hline 1709 & $0.38(0.38)$ & $1.52(2.38)$ & 3.96 & 0.52 & 0.031 & 0.239 \\
\hline 1730 & $0.91(1.13)$ & $1.65(2.75)$ & 2.19 & 0.98 & 0.115 & 0.227 \\
\hline 1734 & $1.29(1.75)$ & $1.39(2.00)$ & 2.21 & 1.21 & 0.127 & 0.217 \\
\hline 1739 & $0.59(0.75)$ & $1.60(2.63)$ & 3.33 & 0.56 & 0.075 & 0.275 \\
\hline 1745 & $0.73(0.88)$ & $1.57(2.50)$ & 1.52 & 0.75 & 0.170 & 0.223 \\
\hline 1751 & $1.29(1.75)$ & $1.56(2.50)$ & 2.00 & 0.73 & 0.186 & 0.254 \\
\hline 1754 & $0.93(1.00)$ & $1.44(2.13)$ & 3.21 & 0.71 & 0.117 & 0.233 \\
\hline JF3N1-1 & $0.47(0.63)$ & $1.61(2.63)$ & 3.63 & 0.44 & 0.134 & 0.156 \\
\hline Control & $0.00(0.00)$ & $1.52(2.38)$ & 4.00 & 0.71 & 0.000 & 0.258 \\
\hline Disease $\times$ isolate & $P<0.0001$ & $\ldots$ & $P=0.0002$ & $\ldots$ & $P<0.001$ & $\ldots$ \\
\hline $\mathrm{LSD}_{0.05}$ & 0.36 & $\ldots$ & 0.92 & $\ldots$ & 0.061 & $\ldots$ \\
\hline
\end{tabular}

a $P$ values and least significant differences (LSDs) are for transformed data. Results represent pooled data of two experiments.

${ }^{\mathrm{b}} \mathrm{np}-\mathrm{BNR}=$ nonpathogenic binucleate Rhizoctonia $\mathrm{spp}$.

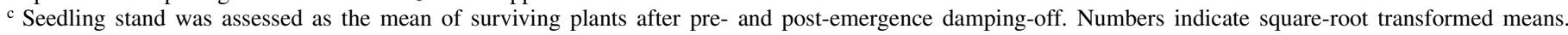
Figures in brackets are untransformed means.

TABLE 5. Disease incidence and shoot dry weight of protected and chemically induced cotton seedlings after the addition of Rhizoctonia solani AG-4 ${ }^{\text {a }}$

\begin{tabular}{|c|c|c|c|c|c|c|}
\hline \multirow[b]{3}{*}{ np-BNR isolates ${ }^{b}$} & \multicolumn{3}{|c|}{ Dry weight (g) } & \multicolumn{3}{|c|}{ Hypocotyl rot severity (0 to 5 ) } \\
\hline & \multicolumn{6}{|c|}{$\mathrm{BTH}(\mathrm{ppm})^{\mathrm{c}}$} \\
\hline & 0 & 20 & 50 & 0 & 20 & 50 \\
\hline 1707 & 0.329 & 0.279 & 0.255 & 0.48 & 0.98 & 0.54 \\
\hline 1734 & 0.313 & 0.259 & 0.250 & 0.73 & 0.92 & 1.15 \\
\hline 1745 & 0.285 & 0.260 & 0.293 & 0.29 & 1.16 & 1.13 \\
\hline 1751 & 0.308 & 0.301 & 0.278 & 0.50 & 0.82 & 0.13 \\
\hline$\ldots$ & 0.332 & 0.283 & 0.246 & 3.54 & 1.53 & 1.70 \\
\hline
\end{tabular}

a Values are means of eight replicates. Results represent pooled data of two experiments.

${ }^{\mathrm{b}} \mathrm{np}-\mathrm{BNR}=$ nonpathogenic binucleate Rhizoctonia spp. Protected and chemically induced seedlings were infected with $R$. solani.

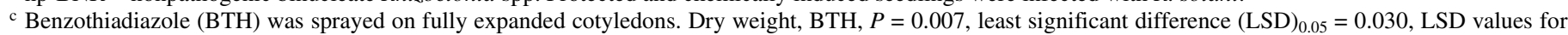
comparison across a row. Hypocotyl rot severity, isolate $\times \mathrm{BTH}$, not significant, $P<0.001, \mathrm{LSD}_{0.05}=0.66$, LSD values for comparison between any two values. 
lieved to be involved in the protection against root and foliar pathogens by np-BNR isolates.

\section{ACKNOWLEDGMENTS}

We thank CSIRO Land and Water, Adelaide, Australia for the financial contribution during S. Jabaji-Hare's sabbatical year; I. Dumitrescu for her technical help in setting up the growth chamber experiments; and B. Harch, CSIRO Mathematical and Information Sciences, Glen Osmond, SA for help in the statistical analyses.

\section{LITERATURE CITED}

1. Alabouvette, C., Lemanceau, P., and Steinberg, C. 1996. Use of nonpathogenic Fusarium oxysporum and fluorescent Pseudomonads to control Fusarium wilts. Pages 155-164 in: Advances in Biological Control of Plant Diseases. T. Wenhua, R. J. Cook, and A. Rovira, eds. China Agricultural University Press, Beijing.

2. Asaka, O., and Shoda, M. 1996. Biocontrol of Rhizoctonia solani damping-off of tomato with Bacillus subtilis RB14. Appl. Environ. Microbiol. 62:4081-4085.

3. Bell, A. 1984. Cotton protection practices in the USA and the world. Pages 288-309 in: American Society of Agronomy Monograph. 24, sect. B., Diseases. R. J. Kohel and C. F. Lewis, eds. The American Society for Agronomy, Madison, WI.

4. Benhamou, N., and Belnager, R. 1998. Induction of systemic resistance to Pythium damping-off in cucumber plants by benzothiadiazole: Ultrastructure and cytochemistry of the host response. Plant J. 14:12-21.

5. Benhamou, N., and Belanger, R. 1998. Benzothiadiazole-mediated induced resistance to Fusarium oxysporum f. sp. radicis-lycopersici in tomato. Plant Physiol. 118:1203-1212.

6. Bigirimana, J., De Meyer, G., Poppe, J., Elad, Y., and Hofte, M. 1997. Induction of systemic resistance on bean (Phaseolus vulgaris) by Trichoderma harzianum. Med. Fac. Landbouwwet. Univ. Gent. 62:1001-1007.

7. Brock, P. M., Inwood, J. R. B., and Deverall, B. J. 1994. Systemic induced resistance to Alternaria macrospora in cotton (Gossypium hirsutum). Aust. Plant Pathol. 23:81-85.

8. Buzi, A., Chilosi, G., De Silo, D., and Magro, P. 2004. Induction of resistance in melon to Didymella bryoniae and Sclerotinia sclerotiorum by seed treatments with acibenzolar-S-methyl and methyl jasmonate but not with salicylic acid. J. Phytopathol. 152:34-42.

9. Cardoso, J. E., and Echandi, E. 1987. Nature of protection of bean seedlings from Rhizoctonia root rot by a binucleate Rhizoctonia-like fungus. Phytopathology 77:1548-1551

10. Colson-Hanks, E. S., and Deverall, B. J. 2000. Effect of 2,6-dichloroisonicotinic acid, its formulation materials and benzothiadiazole on systemic resistance to Alternaria leaf spot in cotton. Plant Pathol. 49:171178.

11. Conrath, U., Thulke, O., Katz, V., Schwindling, S., and A. Kohler. 2001. Priming as a mechanism in induced systemic resistance of plants. Eur. J. Plant Pathol. 107:113-119.

12. Cordier, C., Pozo, M. J., Barea, J. M., Gianinazzi, S., and GianinazziPearson, V. 1998. Cell defense responses associated with localized and systemic resistance to Phytophthora parasitica induced in tomato by an arbuscular mycorrhizal fungus. Mol. Plant-Microbe Interact. 11:10171028.

13. Dann, E. K., Diers, B., Byrum, J., and Hammerschmidt, R. 1998. Effect of treating soybean with 2,6-dichloroisonicotinic acid (INA) and benzothiadiazole (BTH) on seed yields and the level of disease caused by Sclerotinia sclerotiorum in field and greenhouse studies. Eur. J. Plant Pathol. 104:271-278.

14. De Meyer, G., Bigirimana, J., Elad, Y., and Höfte, M. 1998. Induced systemic resistance in Trichoderma harzianum T39 biocontrol of Botrytis cinerea. Eur. J. Plant Pathol. 104:279-286.

15. Dudal, R. 1968. Definition of soil units for the soil map of the world. World Soil Res. Rep. No. 33. FAO, Rome.

16. Friedrich, L., Lawton, K., Ruess, W., Masner, P., Specker, N., Gutrella, M., Meier, B., Dincher, S., Staub, T., Uknes, S., Meteraux, J. P., Kessmann, H., and Ryals, J. 1996. A benzothiadiazole derivative induces systemic acquired resistance in tobacco. Plant J. 10:61-70.

17. Fuch, J.-G., Moenne-Loccoz, Y., and Defago, G. 1999. Ability of nonpathogenic Fusarium oxysporum Fo47 to protect tomato against Fusarium wilt. Biol. Control 14:105-110.

18. Görlach, J., Volrath, S., Knauf-Beiter, G., Hengy, G., Beckhove, U., Kogel, K. H., Oostendorp, M., Staub, T., Ward, E., Kessmann, H., and Ryals, J. 1996. Benzothiadiazole, a novel class of inducers of systemic acquired resistance, activates gene expression and disease resistance in wheat. Plant Cell 8:629-643.
19. Hagedorn, C., Gould, W. D., and Bardinelli, T. R. 1989. Rhizobacteria of cotton and their repression of seedling disease pathogens. Appl. Environ. Microbiol. 55:2793-2797.

20. Hammerschmidt, R. 1999. Induced disease resistance: How do induced plants stop pathogens? Physiol. Mol. Plant Pathol. 55:77-84.

21. Harman, G. E., Howell, C. R., Viterbo, A., Chet, I., and Lorito, M. 2004. Trichoderma species-opportunistic, avirulent plant symbionts. Nat. Rev. Microbiol. 21:43-56.

22. Harris, A. R., and Adkins, P. G. 1999. Versatility of fungal and bacterial isolates for biological control of damping-off caused by Rhizoctonia solani and Pythium spp. Biol. Control 15:10-18.

23. Harris, A. R., Schisler, D. A., Neate, S. M., and Ryder, M. H. 1994. Suppression of damping-off caused by Rhizoctonia solani, and growth promotion, in bedding plants by binucleate Rhizoctonia spp. Soil Biol. Biochem. 26:263-268.

24. Harris, A. R., Schisler, D. A., and Ryder, M. H. 1993. Binucleate Rhizoctonia isolates control damping-off caused by Pythium ultimum var. sprangiiferum and promote growth in Capsicum and Celosia seedling in pasteurized potting medium. Soil Biol. Biochem. 25:909-914.

25. Herr, L. J. 1988. Biocontrol of Rhizoctonia crown and root rot of sugar beet by binucleate Rhizoctonia spp. and Laetisaria arvalis. Ann. Appl. Biol. 113:107-118.

26. Herr, L. J. 1995. Biological control of Rhizoctonia solani by binucleate Rhizoctonia spp. and hypvirulent $R$. solani agent. Crop Prot. 14:179-186.

27. Hillocks, R. J. 1992. Cotton Diseases. CAB International, Wallingford, Oxon, UK.

28. Howell, C. R. 1991. Biological control of Pythium damping-off of cotton with seed coating preparations by Gliocladium virens. Phytopathology 81:739-741.

29. Howell, C. R., DeVay, J. E., Garber, R. H., and Batson, W. E. 1997. Field control of cotton seedling diseases with Trichoderma virens in combination with fungicide seed treatment. J. Cotton Sci. 1:15-20.

30. Howell, C. R., Hanson, L. E., Stipanovic, R. D., and Puckhaber, L. S. 2000. Induction of terpenoid synthesis in cotton roots and control of Rhizoctonia solani by seed treatment with Trichoderma virens. Phytopathology 90:248-252.

31. Hwang, J., and Benson, D. M. 2003. Expression of induced systemic resistance in poinsettia cuttings against Rhizoctonia stem rot by treatment of stock plants with binucleate Rhizoctonia. Biol. Control 27:73-80.

32. Icheilevich-Auster, Sneh, B., Kotlin, Y., and Barash, I. 1985. Suppression of damping-off caused by Rhizoctonia species by a non-pathogenic isolate of $R$. solani. Phytopathology 75:1080-1084.

33. Isbell, R. F. 1996. The Australian Soil Classification. CSIRO Publications, Melbourne, Australia.

34. Jabaji-Hare, S. H., Chamberland, H., and Charest, P. M. 1999. Cell wall alterations in hypocotyls of bean seedlings protected from Rhizoctonia stem canker by a binucleate Rhizoctonia isolate. Mycol. Res. 103:10351043.

35. Jensen, B. D., Latunde-Dada, A. O., Hudson, D., and Lucas, J. A. 1998. Protection of Brassica seedlings against downy mildew and damping-off by seed treatment with CGA 245704, an activator of systemic acquired resistance. Pestic. Sci. 52:63-69.

36. Koike, N., Hyakumachi, M., Kageyama, K., Tsuyumu, S., and Doke, N. 2001. Induction of systemic resistance in cucumber against several diseases by plant growth promoting fungi: Lignification and superoxide generation. Eur. J. Plant Pathol. 107:523-533.

37. Kuc, J. 1995. Phytoalexins, stress metabolism, and disease resistance in plants. Annu. Rev. Phytopathology. 33:275-297.

38. Kuc, J. 2001. Concepts and direction of induced resistance in plants and its application. Eur. J. Plant Pathol. 107:7-12.

39. Lewis, J. A., and Papavizas, G. C. 1991. Biocontrol of cotton damping-off caused by Rhizoctonia solani in the field with formulations of Trichoderma spp. and Gliocladium virens. Crop Prot. 10:396-402.

40. Masuhara, G., Neate, S. M., and Schisler, D. A. 1994. Characteristics of some Rhizoctonia spp. from South Australian plant nurseries. Mycol. Res. 98:83-87.

41. Meteraux, J. P., Ahl Goy, P., Staub, T., Speich, J., Steinemann, A., Ryals, J., and Ward, E. 1991. Induced systemic resistance in cucumber in response to 2,6-dichloro-isonicotinic acid and pathogens. Pages 432-439 in: Advances in Molecular Genetics of Plant-Microbe Interactions. H. Hennecke and D. P. S. Verma, eds. Kluwer Academic Publishers, Dordrecht, The Netherlands.

42. Ogle, H. J., Stirling, A. M., and Dart, P. J. 1993. Pathogenicity of fungi associated with seedling disease of cotton. Aust. J. Exp. Agric. 33:923929.

43. Oostendorp, M., Kunz, W., Dietrich, B., and Staub, T. 2001. Induced resistance in plants by chemicals. Eur. J. Plant Pathol. 107:19-28.

44. Pascual, C. B., Raymundo, A. D., and Hayakumachi, M. 2000. Efficacy of hypovirulent binucleate Rhizoctonia sp. to control banded leaf and sheath blight in corn. J. Gen. Plant Pathol. 66:95-102. 
45. Poromarto, S. H., Nelson, B. D., and Freeman, T. P. 1998. Association of binucleate Rhizoctonia with soybean and mechanism of biocontrol of Rhizoctonia solani. Phytopathology 88:1056-1067.

46. Ryals, J. A., Neuemschwander, K. H., Willitis, M. G., Molina, A., Steiner, H.-Y., and Hunt, M. D. 1996. Systemic acquired resistance. Plant Cell 8:1809-1819.

47. Schweitzer, P., Schlagenhauf, E., Scharffrath, U., and Dudler, R. 1999. Different patterns of host genes are induced in rice by Pseudomonas syringae, a biological inducer of resistance and the chemical inducer benzothiadiazole (BTH). Eur. J. Plant Pathol. 105:659-665.

48. Shtienberg, D. 1996. Variables associated with intensity of Alternaria leaf spot in Pima Cotton. Phytopathology 86:123-128.

49. Siegrest, J., Glenewinkel, D., Kolle, C., and Scmidtke, M. 1997. Chemically induced resistance in green bean against bacterial and fungal pathogens. J. Plant Dis. Prot. 104:599-610.

50. Siwek, K., Harris, A. R., and Scott, E. S. 1997. Mycoparasitism of Pythium ultimum by antagonistic binucleate Rhizoctonia isolates in agar media on capsicum seeds. Phytopathol. Z. 145:417-423.

51. Sneh, B. 1996. Non-pathogenic isolates of Rhizoctonia spp. (np-R) and their role in biological control. Pages 473-483 in: Rhizoctonia Species: Taxonomy, Molecular Biology, Ecology, Pathology and Disease Control. B. Sneh, S. Jabaji-Hare, S. Neate, and G. Dijst, eds. Kluwer Academic Publishers, Dordrecht, The Netherlands.

52. Sneh, B., Burpee, L., and Ogoshi, A. 1991. Identification of Rhizoctonia Species. The American Phytopathological Society, St. Paul, MN.
53. Sneh, B., and Ichielevich-Auster, M. 1998. Induced resistance of cucumber seedlings caused by some non-pathogenic Rhizoctonia (np-R) isolates. Phytoparasitica 26:27-38.

54. Sweetingham, M. W., and MacNish, G. C. 1994. Rhizoctonia isolation identification and pathogenicity, a laboratory manual, 2nd ed. Miscell. Public. 14/92. Department of Agriculture, Western Australia.

55. Van Loon, L. C., Bakker, P., and Pieterse, C. M. J. 1998. Systemic resistance induced by rhizosphere bacteria. Annu. Rev. Phytopathol. 36:453-483.

56. Villajuan-Abgona, R., Kageyama, K., and Hyakumachi, M. 1996. Biocontrol of Rhizoctonia damping-off of cucumber by non-pathogenic binucleate Rhizoctonia. Eur. J. Plant Pathol. 102:227-235.

57. Watkins, G. M. 1981. Compendium of Cotton Diseases. The American Phytopathological Society, St. Paul, MN.

58. Xue, L., Brisson, L., and Jabaji-Hare, S. H. 1997. Activation of defense mechanisms in bean seedlings protected by non-pathogenic Rhizoctonia solani. (Abstr.) Phytopathology 87(suppl.):S106.

59. Xue, L., Charest, P. M., and Jabaji-Hare, S. H. 1998. Systemic induction of peroxidases, 1,3-beta-glucanases, chitinases, and resistance in bean plants by binucleate Rhizoctonia species. Phytopathology 88:359-365.

60. Zaki, K., Misaghi, I. J., and Heydari, A. 1998. Control of cotton seedling damping-off in the field by Burkholderia (Pseudomonas) cepacia. Plant Dis. 82:291-293.

61. Zehnder, G. W., Murphy, J. F., Sikora, E. J., and Kloepper, J. 2001. Application of Rhizobacteria for induced resistance. Eur. J. Plant Pathol. 107:39-50. 